This item was submitted to Loughborough's Research Repository by the author.

Items in Figshare are protected by copyright, with all rights reserved, unless otherwise indicated.

\title{
In situ synthesis of star copolymers consisting of a polyhedral oligomeric silsesquioxane core and poly(2,5-benzimidazole) arms for high-temperature proton exchange membrane fuel cells
}

\section{PLEASE CITE THE PUBLISHED VERSION}

https://doi.org/10.1002/er.5571

\section{PUBLISHER}

John Wiley \& Sons Ltd

\section{VERSION}

AM (Accepted Manuscript)

\section{PUBLISHER STATEMENT}

This is the peer reviewed version of the following article: LI, T. ... et al., 2020. In situ synthesis of star copolymers consisting of a polyhedral oligomeric silsesquioxane core and poly(2,5-benzimidazole) arms for high-temperature proton exchange membrane fuel cells. International Journal of Energy Research, 44 (11), pp.8769-8780, which has been published in final form at https://doi.org/10.1002/er.5571. This article may be used for non-commercial purposes in accordance with Wiley Terms and Conditions for Use of Self-Archived Versions.

\section{LICENCE}

CC BY-NC-ND 4.0

\section{REPOSITORY RECORD}

Li, Tao, Fang Luo, Xudong Fu, Lanxin Li, Jiayuan Min, Rong Zhang, Shengfei Hu, et al.. 2020. "In Situ Synthesis of Star Copolymers Consisting of a Polyhedral Oligomeric Silsesquioxane Core and Poly(2,5benzimidazole) Arms for High-temperature Proton Exchange Membrane Fuel Cells". Loughborough University. https://hdl.handle.net/2134/12464003.v1. 
INTERNATIONAL JOURNAL OF

\section{ENERGY RESEARCH}

\section{In-situ synthesis of star copolymers consisting of a POSS core and poly(2,5-benzimidazole) arms for high temperature PEMFCs}

\begin{tabular}{|c|c|}
\hline Journal: & International Journal of Energy Research \\
\hline Manuscript ID & ER-20-14947.R1 \\
\hline Wiley - Manuscript type: & Research Article \\
\hline $\begin{array}{r}\text { Date Submitted by the } \\
\text { Author: }\end{array}$ & $\mathrm{n} / \mathrm{a}$ \\
\hline Complete List of Authors: & $\begin{array}{l}\text { Li, Tao; Hubei University of Technology, School of Materials and } \\
\text { Chemical Engineering } \\
\text { Luo, Fang; Hubei University of Technology, School of Materials and } \\
\text { Chemical Engineering } \\
\text { Fu, Xudong; Hubei University of Technology, School of Materials and } \\
\text { Chemical Engineering } \\
\text { Li, Lanxin; Hubei University of Technology, School of Materials and } \\
\text { Chemical Engineering } \\
\text { Min, Jiayuan; Hubei University of Technology, School of Materials and } \\
\text { Chemical Engineering } \\
\text { Zhang, Rong; Hubei University of Technology, School of Materials and } \\
\text { Chemical Engineering } \\
\text { Hu, Shengfei; Hubei University of Technology, School of Materials and } \\
\text { Chemical Engineering } \\
\text { Zhao, Feng; Wuhan Troowin Power System Technology Co., Ltd. } \\
\text { Li, Xiao; Wuhan Troowin Power System Technology Co., Ltd. } \\
\text { Zhang, Yanhua; Hubei University of Technology, School of Materials and } \\
\text { Chemical Engineering } \\
\text { Bao, Xujin; Loughborough University, Materials Department } \\
\text { Liu, Qingting; Hubei University of Technology, School of Materials and } \\
\text { Chemical Engineering }\end{array}$ \\
\hline Keywords: & $\begin{array}{l}\text { Proton exchange membrane, Poly }(2,5 \text {-benzimidazole), Polyhedral } \\
\text { oligomeric silsesquioxane, Star copolymer, Film-forming }\end{array}$ \\
\hline
\end{tabular}

\section{SCHOLARONE" Manuscripts}




\title{
In-situ synthesis of star copolymers consisting of a POSS core and poly(2,5-benzimidazole) arms for high temperature PEMFCs
}

Tao $\mathrm{Li}^{\mathrm{a}}$ \& , Fang $\mathrm{Luo}^{\mathrm{a}}$ \&, Xudong $\mathrm{Fu}^{\mathrm{a}}$ * , Lanxin $\mathrm{Li}^{\mathrm{a}}$, Jiayuan Min ${ }^{\mathrm{a}}$, Rong Zhang ${ }^{\mathrm{a}}$, Shengfei $\mathrm{Hu}^{\mathrm{a}}$, Feng Zhao ${ }^{\mathrm{a}, \mathrm{b}}$, Xiao Lia, b, Yanhua Zhang ${ }^{\mathrm{a}}$, Xujin Bao ${ }^{\mathrm{a}, \mathrm{c}}$, Qingting Liu ${ }^{\mathrm{a}, *}$

${ }^{a}$ Hubei Provincial Key Laboratory of Green Materials for Light Industry, School of Materials and Chemical Engineering, Hubei University of Technology, Wuhan, 430068, China

${ }^{\mathrm{b}}$ Wuhan Troowin Power System Technology Co., Ltd., Wuhan, 430079, China

${ }^{\mathrm{c}}$ Department of Materials, Loughborough University, Leicestershire, LE11 3NW, UK

\& These authors contributed equally to this work

E-mail: liuqt@hbut.edu.cn (Q. Liu); fuxudong@hbut.edu.cn (X.Fu)

\begin{abstract}
Star copolymers with good film-forming and mechanical properties were insitu synthesized for fabricating proton exchange membranes. The monomers of 3,4diaminobenzoic acid were first grafted onto glycidyl-polyhedral oligomeric silsesquioxane (G-POSS) cores and then propagated to the poly(2,5-benzimidazole) (ABPBI) chains. The introduction of the star copolymer improves the movement of the ABPBI polymer chains, resulting in a lower internal viscosity and larger free volume that favor increased membrane flatness and absorbilities of water and phosphoric acid molecules, respectively. It was found that the star copolymers with $1.0 \mathrm{wt} \%$ of incorporated POSS (ABPBI-1.0POSS) had the best balance of the acid retentivity and film-forming property as well as mechanical properties that are desirable for proton exchange membranes without PA loss operating at high temperatures. The enhanced cell performance characteristics obtained using the ABPBI-1.0POSS-based membranes indicate that star copolymers are promising materials for use in high temperature proton exchange membrane fuel cells.
\end{abstract}




\section{Graphical abstract}

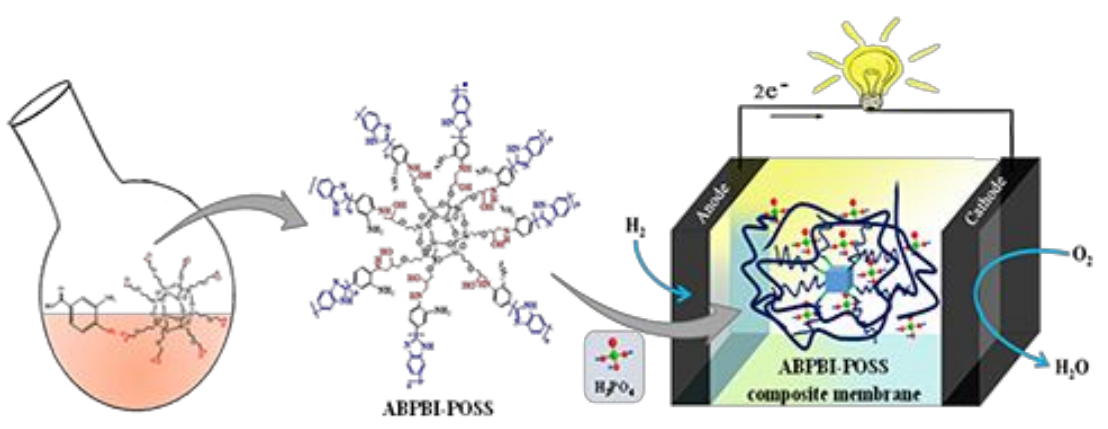

Keywords: Proton exchange membrane; Poly(2,5-benzimidazole); Polyhedral oligomeric silsesquioxane; Star copolymer; Film-forming

\section{Introduction}

Due to their wide range of potential applications in electric vehicles, combined heat and power systems, and auxiliary power units, high temperature-proton exchange membrane fuel cells (HT-PEMFCs) $\left(100-200{ }^{\circ} \mathrm{C}\right)$ have attracted intense research attention [1-4]. Raising the working temperature of PEMFCs to above $100{ }^{\circ} \mathrm{C}$ is highly favorable compared to their operation at low temperatures (i.e. below $100{ }^{\circ} \mathrm{C}$ ) due to advantages such as high catalyst tolerance to carbon monoxide, simple heat and water management, and consequently high fuel cell efficiency [5-7]. Phosphoric acid-doped polybenzimidazole (PA-PBI) membrane is still the most widely studied proton exchange membrane (PEM) in the high temperature range of $120-180{ }^{\circ} \mathrm{C}$ [7-10]. Among PBI-type polymers (PBIs), ABPBI has been shown to be a promising material due to its unique combination of low cost, single-step synthesis process, and high acid absorbility [11]. Unfortunately, PBIs-based cells are strictly limited to operation in the $120-180{ }^{\circ} \mathrm{C}$ range only in order to avoid free PA leaching in hydrous atmosphere at the temperatures below the lower limit of $120^{\circ} \mathrm{C}$ and to avoid degradation above the upper 
limit of $180^{\circ} \mathrm{C}[12,13]$. Furthermore, PA-PBIs-based membranes often show a tradeoff relationship between the PA absorbance on the one hand and film-forming and mechanical stability on the other hand [2]. To design PBI-based PEMs with excellent electrochemical performance and stability, the construction of the membrane microstructure and proton transfer channels are critical [14].Thus, one of the greatest challenges for the commercialization and effective operation of PBI in HT-PEM fuel cells is to achieve high proton conductivity, good film-forming ability and good mechanical stability while avoiding the disadvantages of free PA.

Much effort has been exerted for the development of PBIs-based PEMs for hightemperature applications. The developed approaches [5, 11, 15-17] include: 1) linking PA through either crosslinked polymer matrices or basic; 2) impregnation of hygroscopic inorganic fillers to retain PA, and 3) introduction of immobilized proton carriers to partially or fully replace PA. Among these approaches, the use of inorganicnanoparticle-embedded composite membranes is the most favorable due to the simple synthesis and low cost of these membranes. These nanocomposite membranes often show the combined advantages of good mechanical strength, high water and/or acid retention capabilities, and good proton conductivity at elevated temperatures and reduced relative humidity $(\mathrm{RH})[1,18]$. However, the amount of embedded inorganic fillers has been limited due to their strong tendency to aggregation that leads to the deterioration of the mechanical and film-forming properties [19].

Star-shaped polymers consisting of a multifunctional core from which multiple polymer chains (multiarms) radiate have unique properties compared to their linear 
analogues with identical molecular weight and monomer composition [20]. Generally, these star-shaped copolymer have lower internal viscosities than their linear analogues with the same molecular weight, with the internal viscosity dependent on the molecular weight of the arms [21]. Such lower internal viscosity is beneficial for improving the film-forming property. Due to their larger free volume, PEMs with branched polymers show a marked improvement in proton conductivity compared to the corresponding linear polymers. Because their unique three-dimensional networks with enlarged free volume can maintain more water and/or acid, branched polymers have been applied in low-temperature [22-24] and high-temperature PEMs [25, 26].

Polyhedral oligomeric silsesquioxane (POSS) possesses an inorganic core with an $\mathrm{Si}-\mathrm{O}$ framework that can form links with organic groups or reactive groups at its eight vertices [27]. Due to the ease of controlled modification and rational design of the organofunctional groups on POSS, the water retention property of the material can be enhanced by chemically modifying the branch containing the hydrophilic functional group. Meanwhile, groups with specific functionalities can be grafted to POSS so that on the one hand, protons can be transferred independent of water when these functional groups act as proton receptors and donors [28], while on the other hand, the formation of crosslinked structures enhances the mechanical stability and dimensional stability of the composite membranes [26, 29-32].

In this study, organic-inorganic hybrid composite membranes with star copolymers of ABPBI-POSS were prepared to achieve a balance amongst the PA uptake, film-forming property and mechanical stability. Herein, the star copolymer was 
obtained in an efficient in-situ synthesis carried out using the "arm-out" method as shown in Scheme 1. During the synthesis process, an epoxy ring-opening reaction occurred between Glycidyl-POSS and the 3,4-diaminobenzoic acid (DABA) monomer at a low temperature (approximately $80^{\circ} \mathrm{C}$ ), and then the grafted DABA continuously propagated into the ABPBI polymer chains at the elevated temperatures (up to $150{ }^{\circ} \mathrm{C}$ ) to form star copolymers with the typical structure of a POSS as the core and eight ABPBI chains as the arms. The inorganic POSS cores improve the mechanical properties, while the star-shaped copolymers with adjustable arm lengths are expected to reduce the intrinsic viscosity which is desirable for preparing highly flat membranes [33]. Due to the benefits provided by the introduction of POSS, the ABPBI-POSS composite membranes treated by boiling in hot water in order to remove free PA as much as possible show enhanced water uptake, PA retentivity, and proton conductivity. We believe that this study provides a feasible method for the fabrication of a new class of PA-PBIs-based PEMs with a good balance among the PA uptake, film-forming and mechanical properties for use in HT-PEMFCs.

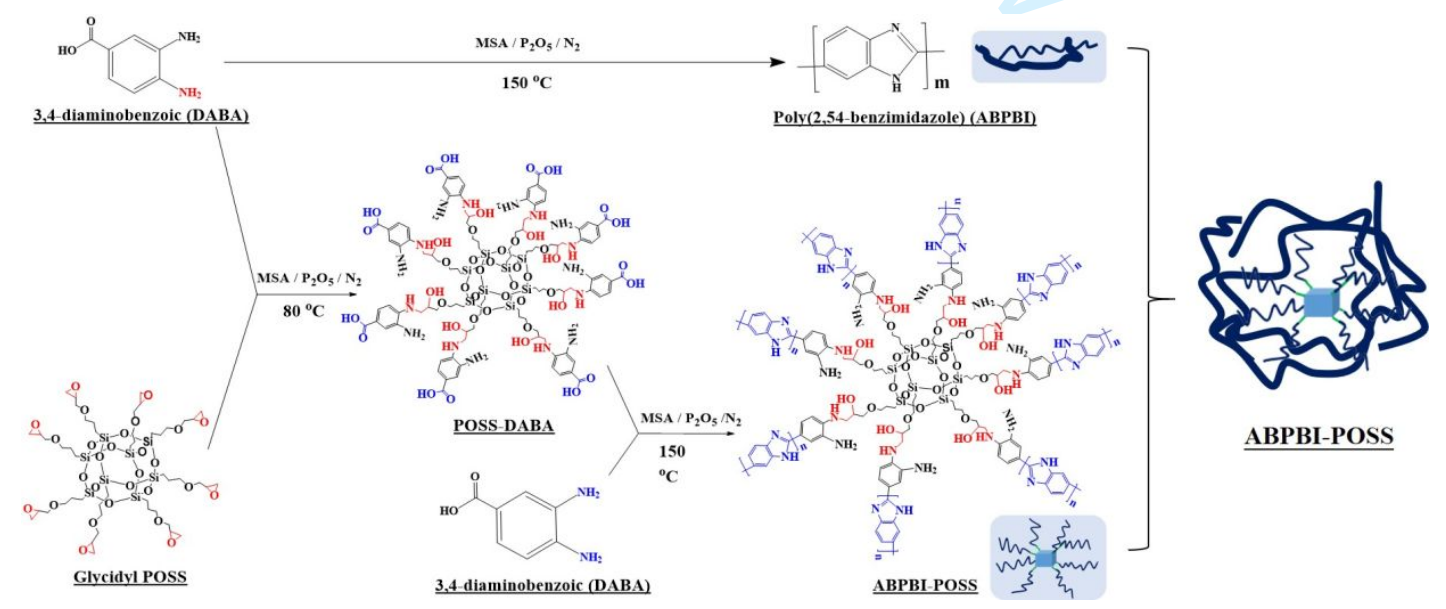

Scheme 1. Schematic illustration of the synthesis procedure.

\section{Experimental}


Materials: Glycidyl-POSS (G-POSS, 99\%) was purchased from Hybrid Plastics (USA). Monomer 3,4-Diaminobenzoic acid (DABA, 98.0\%) was purchased from Beijing J\&K Technology (China). Methane sulfonic acid (MSA, 99.0\%) was purchased from the Aladdin Industrial (China). $\mathrm{P}_{2} \mathrm{O}_{5}(98.0 \%), \mathrm{PA}(85.0 \%), \mathrm{NaOH}(85.0 \%), \mathrm{CHCl}_{3}$ (analytical reagent), DMSO (analytical purity), $\mathrm{NaHCO}_{3}$ (analytical reagent), $\mathrm{C}_{2} \mathrm{H}_{5} \mathrm{OH}$ (99.7\%), $\mathrm{HCl}(36.0-38.0 \%)$ and $\mathrm{H}_{2} \mathrm{SO}_{4}(95.0-98.0 \%)$ were obtained from Sinopharm Chemical Reagent (China). All of the chemicals were used as received without further purification.

Synthesis of star copolymer: DABA $(1.58 \mathrm{~g})$ and a certain mass fraction $(0.5 \%, 1 \%$, $1.5 \%, 2 \%$ ) of POSS were dissolved in MSA and ultrasonicated for $1.5 \mathrm{~h}$. Then, $\mathrm{P}_{2} \mathrm{O}_{5}$ (10 g) was added to the mixture. The reaction was carried out under nitrogen atmosphere, and the temperature was first increased to $80{ }^{\circ} \mathrm{C}$ and held for $0.5 \mathrm{~h}$, and then increased to $150{ }^{\circ} \mathrm{C}$ and held for $2.5 \mathrm{~h}$. The product was boiled in a beaker with a $10 \% \mathrm{NaOH}$ solution at $100{ }^{\circ} \mathrm{C}$ for $2 \mathrm{~h}$ to remove the remaining MSA, and then boiled in deionized water (D.I. water) until $\mathrm{NaOH}$ was completely removed. Finally, the filamentous product was dried in a vacuum oven at $110{ }^{\circ} \mathrm{C}$ for $24 \mathrm{~h}$ to obtain the ABPBI-POSS hybrid composites. The reactions in the synthesis of ABPBI-POSS are illustrated in Scheme 1.

Preparation and characterization of Membranes: Membrane preparation and the characterizations of morphology, thermal stability, intrinsic viscosity, mechanical properties, water uptakes (WUs), PA DLs, oxidative stability and proton conductivities followed the procedures typically used for ABPBI membrane casting [26] as described 
in detail in the ESI.

Single cell performance: The catalyst 40\% Pt/C (Johnson Matthey, UK) was ultrasonically dispersed in an ethanol solution to prepare a catalyst slurry, and then sprayed onto the gas diffusion layer that consisted of Vulcan XC-72 carbon PTFE (20 wt $\%$ ) coated onto a carbon paper (TGPH060, Toray, Japan) to prepare the gas diffusion electrode (GDE) [34], with the Pt loading controlled to be $0.5 \mathrm{mg} / \mathrm{cm}^{2}$. The GDEs and the membrane were assembled by 2 min of hot-pressing at $0.2 \mathrm{MPa}$ and $130{ }^{\circ} \mathrm{C}$ to obtain the membrane electrode assembly (MEA). The polarization curve of the single cell was tested using a homemade fuel cell test system, and the inlet pressure on both sides of the cell was 0.8 bar.

\section{Results and discussion}

Chemical structure analysis: The star copolymers of ABPBI-POSS were prepared by in-situ synthesis in a two-step heating processes that raised the temperature from room temperature to $150^{\circ} \mathrm{C}$. In this study, the successful execution of the epoxy ring-opening reaction between the epoxy groups in G-POSS and the amino groups in monomer DABA to form DABA grafted POSS (POSS-DABA) was easily confirmed by the reaction of the carboxyl protective group as illustrated in the ESI. The FTIR and ${ }^{1} \mathrm{H}$ NMR spectra of the product synthesized using the salt formation of DABA at $80{ }^{\circ} \mathrm{C}$ are shown in Figs. S1 and S2, respectively. As shown in Fig. S1, characteristic peaks were observed for the Si-O cage structure at $1092 \mathrm{~cm}^{-1}$ and for the telescopic vibration of the benzene ring skeleton at $1631 \mathrm{~cm}^{-1}$ from DABA [26], confirming the presence of the POSS and DABA components in the composite materials. Meanwhile, the 
characteristic peak of the epoxy group in G-POSS at $904 \mathrm{~cm}^{-1}$ disappeared; this was attributed to the generation of the $-\mathrm{NH}-\mathrm{O}-$ group, indicating the grafting of the DABA monomer onto G-POSS (POSS-DABA) via the epoxy ring-opening reaction. The ${ }^{1} \mathrm{H}$ NMR curve (Fig. S2) further confirms the chemical structure of POSS-DABA. The peaks at $8.31 \mathrm{ppm}, 7.20 \mathrm{ppm}$, and $6.63 \mathrm{ppm}$ are attributed to the three hydrogen in the benzene ring and $5.33 \mathrm{ppm}$ to the amino group [35], while the peak at $2.01 \mathrm{ppm}$ attributed to the secondary ammonia $[33,36]$ and $0.86 \mathrm{ppm}$ to the hydroxyl. At the same time, the peak at $3.21 \mathrm{ppm}$ corresponding to the proton on the epoxy group $[36,37]$ does not appear in the spectrum of POSS-DABA. These indicate the occurrence of the epoxy ring-opening reaction between the epoxy groups in G-POSS and the amino groups in monomer DABA.

(A)

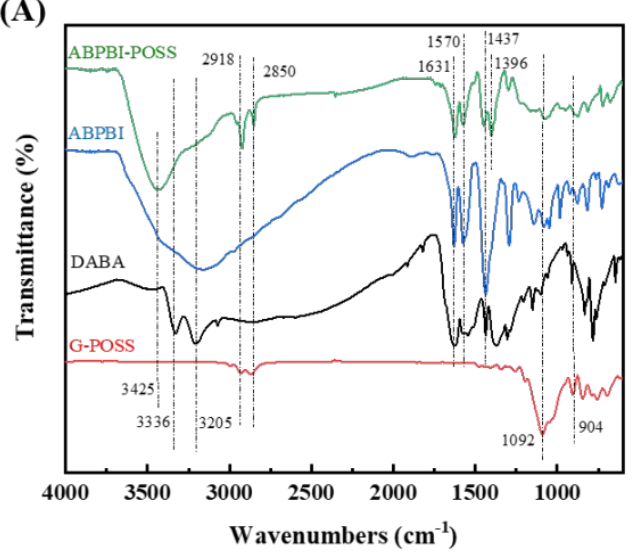

(B)

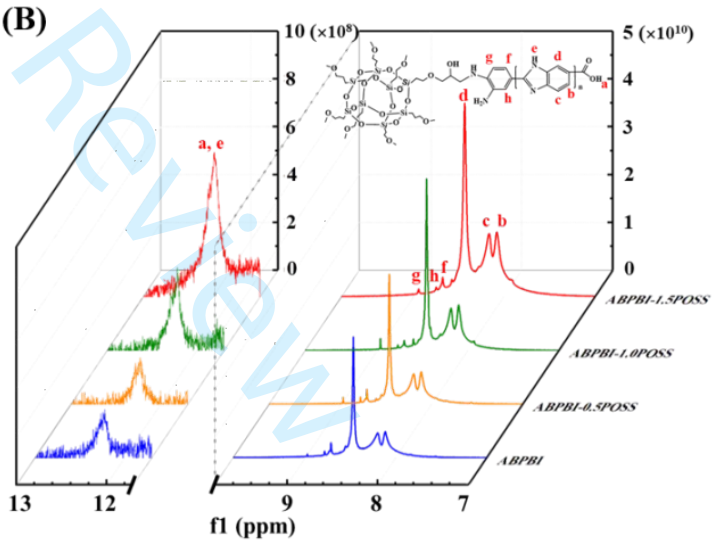

(C)

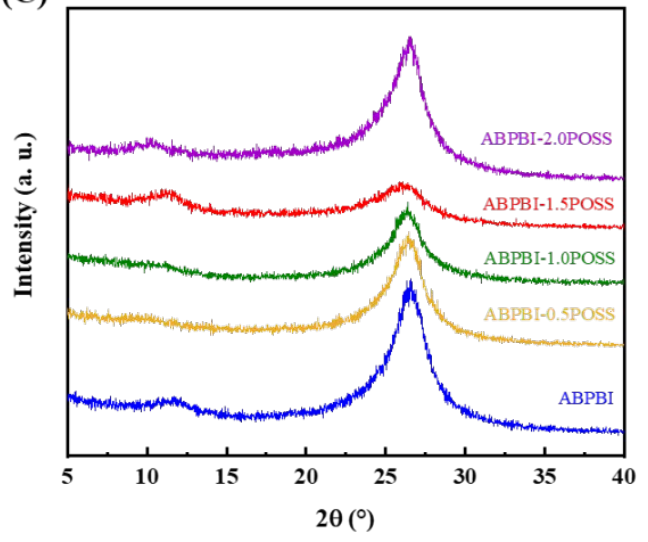

Fig. 1 FTIR (A), ${ }^{1} \mathrm{H}$ NMR (B) and XRD (C) spectra of the ABPBI-POSS copolymer. 
With the reaction temperature raised to $150{ }^{\circ} \mathrm{C}$, the DABA monomer grafted onto POSS-DABA was expected to continuously propagate into the ABPBI polymer chains and ultimately form star copolymers (ABPBI-POSS) with the typical structure of POSS as the core and eight ABPBI chains as the arms. The chemical structure of the star copolymer was confirmed by FTIR spectroscopy as shown in Fig. 1A. The FTIR spectrum of the ABPBI-POSS synthetic product shows the typical characteristics of the ABPBI polymer chain, in particular the benzimidazole group stretching bands at 1631 $\mathrm{cm}^{-1}$ and $1570 \mathrm{~cm}^{-1}[26]$, and the characteristic stretching modes of the $\mathrm{Si}-\mathrm{O}$ in the POSS core at $1092 \mathrm{~cm}^{-1}$ and the grafted $-\mathrm{CH}_{2}-$ groups at $2918 \mathrm{~cm}^{-1}$ and $2850 \mathrm{~cm}^{-1}$. The epoxy group peak at $904 \mathrm{~cm}^{-1}$ disappeared and a broad peak attributed to the $-\mathrm{OH}$ stretching mode appeared at $3425 \mathrm{~cm}^{-1}$, indicating that ABPBI polymer chains were successfully grafted into POSS through the epoxy ring opening reaction to form the ABPBI-POSS copolymer.

In Fig. 1B, the signals for the three protons in benzimidazole are observed at 8.11 (c-H), 8.19 (b-H), 8.47 (a-H) [38], and the weak peak at 12.21 ppm corresponds to $\mathrm{H}$ of both the $-\mathrm{COOH}$ end group and benzene in the ABPBI chain [39]. It is clearly observed that the peak intensity at $12.21 \mathrm{ppm}$ increases with the increased POSS content, implying that a greater amount of the carboxyl groups was retained for the composites with greater POSS content. As the POSS content increases, the number of the repeating units decreases and the arms or grafted ABPBI chains become shorter. Although the "arm-out" method has the limitation that the arm length of the synthesized 
stars cannot be characterized directly, indirect methods such as intrinsic viscosity measurements can be employed to evaluate the characteristics of star copolymers.

The ABPBI polymer has a semi-crystalline structure with the characteristic stacking of ABPBI chains that displays a broad peak at $26.55^{\circ}$ in agreement with the previously obtained results [40]. As shown in Fig. 1C, both the ABPBI membrane and ABPBI-POSS composite membranes display this characteristic peak indicating the existence of semi-crystalline ABPBI chains. It is also found that the peak intensities of the composite membranes are lower than that of ABPBI membrane and first decreased with the POSS content increasing to $1.5 \mathrm{wt} \%$ and then increased with the POSS content increasing to $2.0 \mathrm{wt} \%$. It can be explained that the introduction of the ABPBI-POSS star copolymer must break the ABPBI chain stacking, resulting in the reduction of the peak intensity, while the excessive amount of POSS is responsible for the increasing peak intensity in the ABPBI-2.0POSS sample due to agglomeration.

Film-forming property analysis: The film-forming properties of the membranes were evaluated by intrinsic viscosity measurements and morphology characterization. As observed in Fig. 2a, the intrinsic viscosity decreased with increased POSS content. Based on the analysis of ${ }^{1} \mathrm{H}-\mathrm{NMR}$ spectra presented in Fig. 1B, this effect is attributed to the ABPBI arms in the star-branched structure of ABPBI-POSS and ABPBI polymer chains becoming shorter, leading to the reduced intermolecular entanglement. Thus, intrinsic viscosity can be used as a measure of the ABPBI arm length changes. 

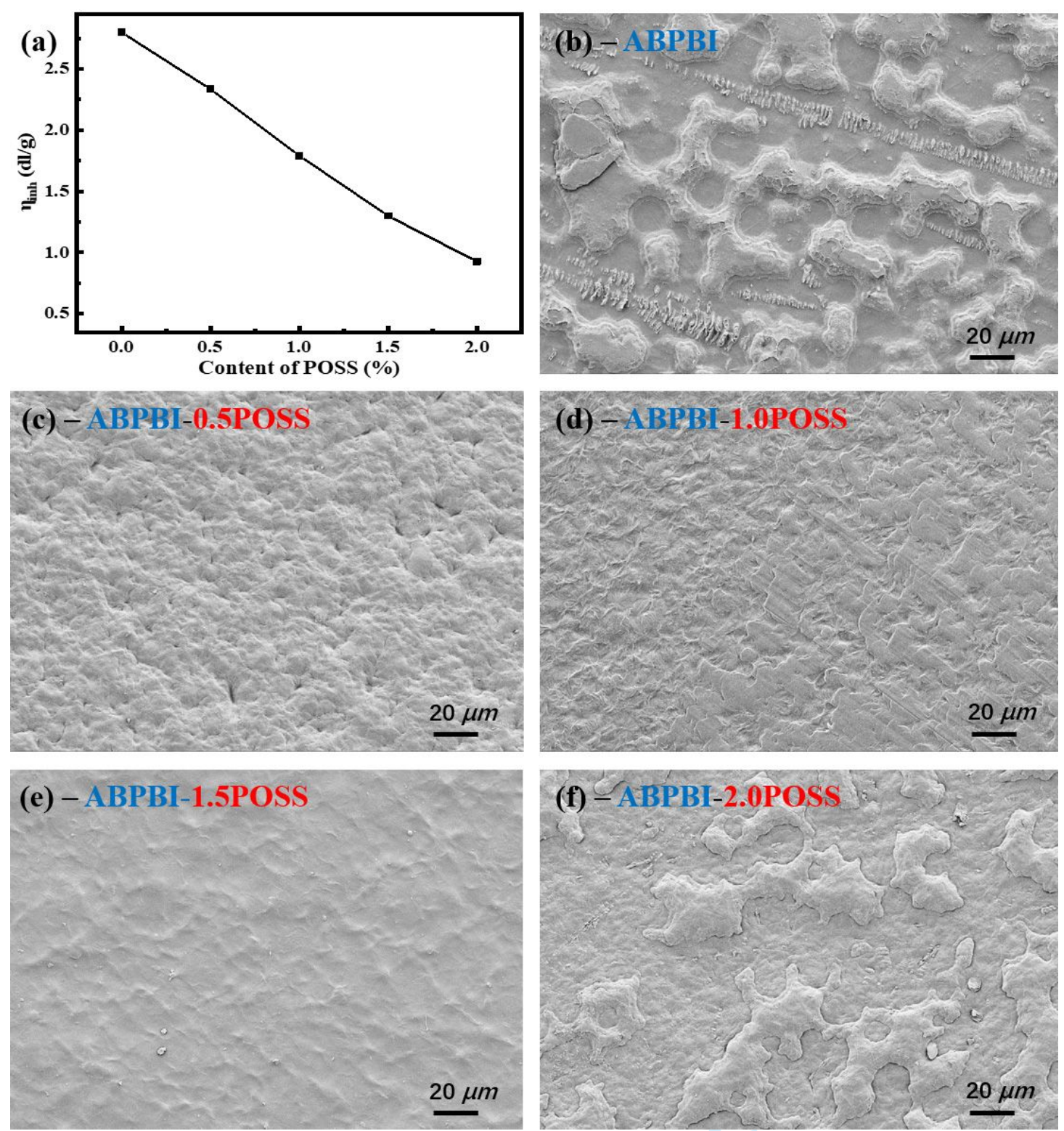

Fig. 2 (a) Intrinsic viscosity; (b-f) SEM images of ABPBI and ABPBI-POSS

membranes. 

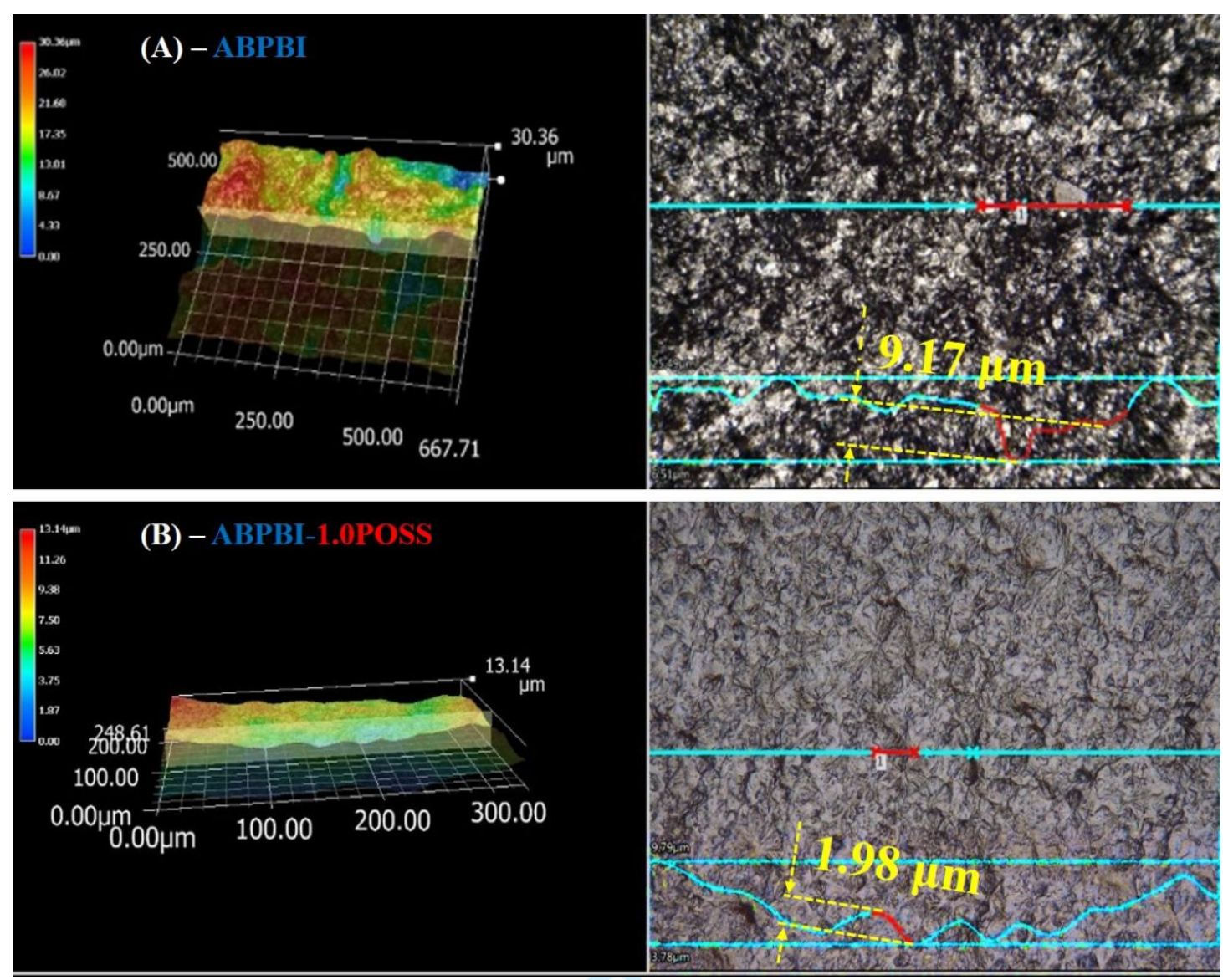

Fig. 3 Evaluation of the surface morphology of the ABPBI membrane (A) and

ABPBI-POSS (B) observed with an optical microscope (Keyence VHX-5000).

Fig. 2b-f and Fig. 3 also show the surface topographies of the ABPBI and ABPBIPOSS membranes. The ABPBI membrane displays an uneven surface with dimples with the lengths of tens of $\mu m$ (Fig. 2b) and the depths of up to $9.17 \mu m$ (Fig. 3A). It is important to mention that as shown in Fig. S3, the ABPBI membrane that did not undergo the acid removal procedure (i.e. before boiling in $\mathrm{NaOH}$ and rinsing with water) clearly shows the residual MSA left in the dimples, indicating that these dimples should be attributed to the uneven evaporation of the MSA solvent.

Compared to the ABPBI membrane, the ABPBI-POSS membranes show relatively uniform surfaces that first become more flat as the POSS content increased 
from $0.5 \mathrm{wt} \%$ to $1.5 \mathrm{wt} \%$ (Fig. 2c-e and Fig. 3B), and then become more rough when the POSS content is further increased to $2.0 \mathrm{wt} \%$ (Fig. 2f). It is known that the ABPBI polymer has a quasi-crystalline form due to the stacking of the ABPBI chains with a $d$ spacing between the two parallel benzimidazole chains of $3.3 \AA$ [41]. This quasicrystalline structure makes it difficult for the MSA solvent to escape when the solution casting method is used to form an ABPBI membrane [40]. The destruction of the ABPBI chains stacking by the star copolymer improved the movement of ABPBI chains, resulting in the greatly enhanced film-forming properties. As the POSS content is increased further, the POSS particles begin to agglomerate in the ABPBI-2.0POSS sample, giving rise to a rough topology. The surface morphologies of the ABPBI and ABPBI-POSS membranes were also investigated by AFM. As shown in Fig. S4, compared to the relatively flat surface of the ABPBI-POSS membranes, the ABPBI membrane shows a clear pit that is ascribed to the uneven MSA evaporation. Considering the need for a balance between the film-forming and mechanical properties, the ABPBI-1.0POSS sample was considered to have the optimal composition for PEM fabrication.

Thermal stability, mechanical properties, water and phosphoric acid absorbilities, volume swelling rate and oxidative stability: The thermal stabilities of membranes were measured with the results shown in Fig. S5. The thermal weight loss before $300^{\circ} \mathrm{C}$ is mainly due to the volatilization of the bound water in the polymer and the elimination of low molecular weight polymer [26]. The heavier weight loss before $300{ }^{\circ} \mathrm{C}$ of the ABPBI-0.5POSS and ABPBI-1.0POSS samples compared to that of ABPBI indicates 
they maintain more bound water [27] due to the effect of the star copolymer, and the composite membranes still maintain a good thermal stability that fully meets the operating temperature requirements of HT-PEMFC.

(a)

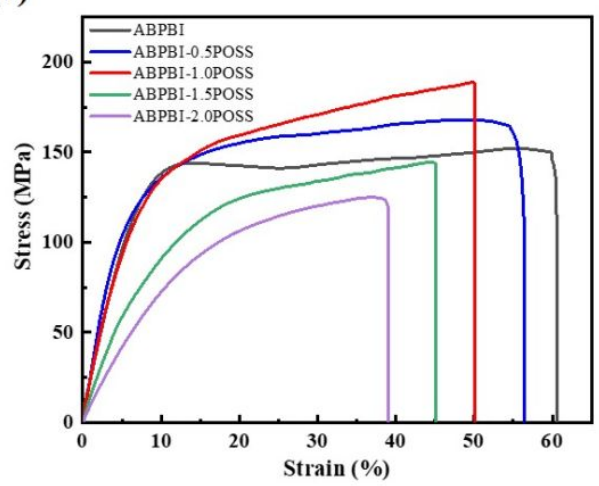

(c)

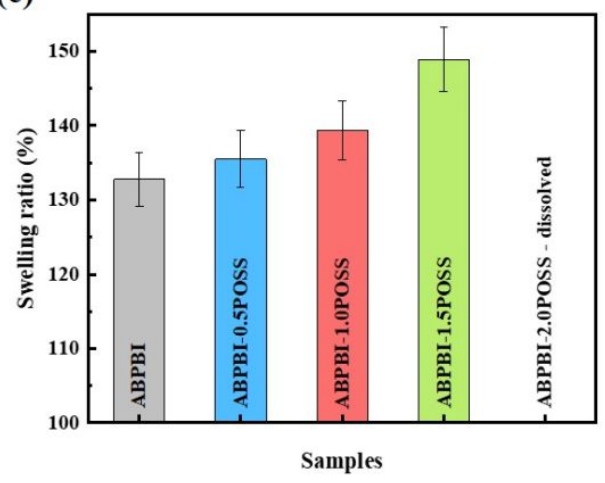

(b)

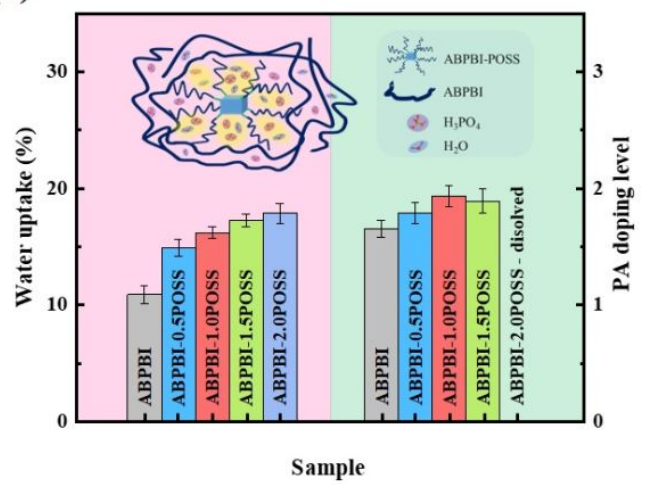

(d)

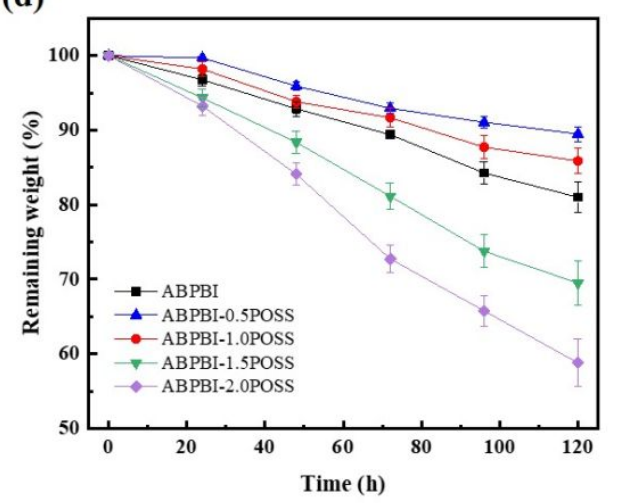

Fig. 4 (a) Stress-strain curves of the ABPBI and ABPBI-POSS; (b) Water uptake (WU) under $98 \% \mathrm{RH} 50{ }^{\circ} \mathrm{C}$ and phosphoric acid (PA) doping level (DL) under $70 \%$ PA solution of the ABPBI and ABPBI-POSS membranes; (c) Swelling ratio after phosphoric acid doping (the ABPBI-2.0POSS sample dissolved in the PA solution); (d) Oxidative stability of the ABPBI and ABPBI-POSS membranes in Fenton's reagent at $70{ }^{\circ} \mathrm{C}$.

Fig. 4a and Table S1 present the mechanical properties of the ABPBI and ABPBIPOSS membranes. With increasing POSS content, the tensile strength of the composite membranes first increased and then decreased. The Young's modulus values of the 
ABPBI-0.5POSS and ABPBI-1.0POSS membranes are greatly higher than that of the ABPBI membrane, while the Young's modulus decreased strongly upon the addition of more than $1.0 \mathrm{wt} \%$ of POSS. For the content of no more than $1.0 \mathrm{wt} \%$, the welldispersed POSS in the ABPBI-POSS membranes improves the mechanical properties; with the content exceeding $1.0 \mathrm{wt} \%$, on the one hand, the star copolymer with shorter arms make the movement of the molecular segment more free leading to the decreased mechanical stability [42], on the other hand, the aggregation of POSS in the ABPBI2.0POSS sample leads to a negative effect on the mechanical properties by generating discontinuities in the polymer phase.

For the effective operation of PA-PBI in HT-PEM fuel cells, it is necessary to achieve high proton conductivity while avoiding the disadvantages of free PA. Therefore, the PA-doped membranes were boiled in hot water to remove the free PA as much as possible. As shown in Fig. 4b, the ABPBI-POSS membranes present higher WU and PA DL values than the pure ABPBI membrane. It is clear that the hydrophilic groups including the benzimidazole groups in the ABPBI chains and the hydroxyl groups generated by the epoxy ring opening as well as the basic benzimidazole groups can contribute the water and acid absorbilities, respectively. As mentioned above, the star copolymer increased the distance between the ABPBI chains and the molecularlevel free volume. More water and PA molecules are present in the enlarged space, resulting in the strong enhancement of water absorbilities and acid retentivities. However, for the $2.0 \mathrm{wt} \%$ POSS content, the ABPBI-2.0POSS sample dissolved in the $70 \%$ PA solution, most likely due to its poor mechanical properties. 
The PA-PBI PEMs often exhibit excessive swelling that degrades the performance of PEMFCs. In Fig. 4c, except for the ABPBI-2.0POSS membrane dissolved in PA solution, the swelling ratios of the remaining ABPBI-POSS membranes increased with the POSS content increasing to $1.5 \mathrm{wt} \%$. As discussed above, the introduction of the star copolymer gave rise to more free space and reduced entanglement of the polymer chains in the composite membranes, resulting in the increased swelling ratio.

The oxidative stability of a PEM is an extremely important parameter for assessing the long-term durability of a cell because the $\cdot \mathrm{OH}$ and $\cdot \mathrm{OOH}$ radicals generated during the cell operation attack the polymer chains, resulting in the degradation of the polymer matrix [18]. As shown in Fig. 4d, the ABPBI-0.5POSS and ABPBI-1.0POSS membranes exhibit better oxidative stability than the pristine ABPBI membrane, while the ABPBI-1.5POSS and ABPBI-2.0POSS samples show poorer oxidative stability. A PBI chain has two types of end groups, namely $-\mathrm{COOH}$ and $-\mathrm{NH}_{2}$. The $-\mathrm{NH}_{2}$ end group is easily oxidizable compared to $-\mathrm{COOH}$ and the inserted $-\mathrm{NH}-$ group, and is mainly responsible for the oxidative and thermal stability of the whole polymer chain. The amount of the $-\mathrm{NH}_{2}$ end groups should is greatly reduced by the epoxy-ring opening reaction, and therefore the star copolymer (ABPBI-0.5POSS and ABPBI-1.0POSS) shows better oxidative stability than the pristine ABPBI polymer. However, for the ABPBI-1.5POSS and ABPBI-2.0POSS samples, the shortened polymer chains and enlarged free spaces imply that the polymer chains are more easily attached by radicals. Based on these results combined with the above analysis of mechanical stabilities and 
film-forming properties, it was concluded that ABPBI-1.0POSS was the most suitable material for PEM fabrication.

Proton conductivity and single cell performance: The proton conductivity results for the PA-doped membranes based on ABPBI and ABPBI-POSS membranes with similar PA DLs are shown in Fig. 5A, and it is observed that the proton conductivities of the ABPBI-POSS composite membranes were higher than that of the ABPBI membrane at the temperature range of $120-180^{\circ} \mathrm{C}$, with the best conductivity obtained for ABPBI1.0POSS. Generally, the higher PA DL indicates higher proton conductivity. Since these PEMs had similar PA DLs, the improvement of proton conductivities from ABPBI-POSS composite membranes should be attributed to the enhanced ability of PA molecule movement, which is also consistent with the relative Ea values shown in Fig. 5A. The $E_{a}$ value indicates the ease of proton hopping and rotation of both donor and acceptor, and a larger value implies that a higher enthalpy is required for the proton transfer. As reported in [2], due to the lower $E_{a}$ of proton migration, the proton conduction through $\mathrm{H}_{2} \mathrm{O}$, PA, and ionic- or $\mathrm{H}$-bonds is more effective than that through the PA-imidazole link in the PA-PBIs membranes. Therefore, the lower $E_{a}$ values obtained using the ABPBI-POSS membranes imply that the enhanced absorbilities of water and PA contribute to the improvement in the proton conductivities. Comparison to the proton conductivities reported in the literature (Table S2) shows that the proton conductivity values of ABPBI-1.0POSS in the anhydrous conditions such as 0.019 $\mathrm{S} / \mathrm{cm}$ at $160^{\circ} \mathrm{C}$ and $0.022 \mathrm{~S} / \mathrm{cm}$ at $180{ }^{\circ} \mathrm{C}$ are higher than those of the other 
ABPBI/POSS hybrid membranes, and are also comparable to those of the ABPBI and PBI membranes with embedded inorganic particles $[3,11,16]$.

(A)

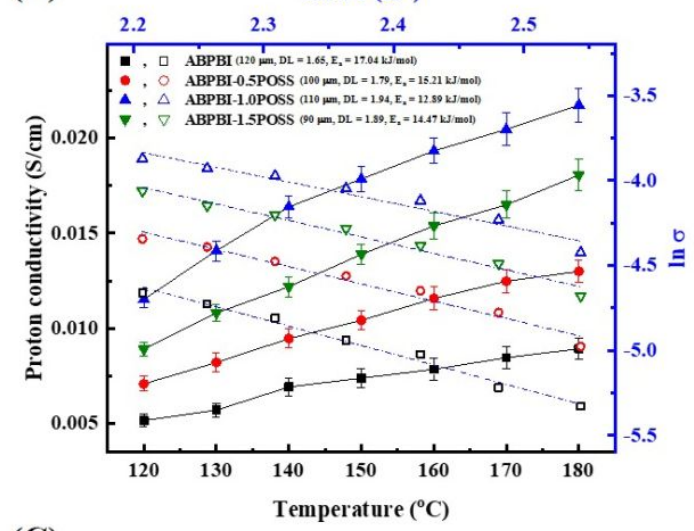

(C)

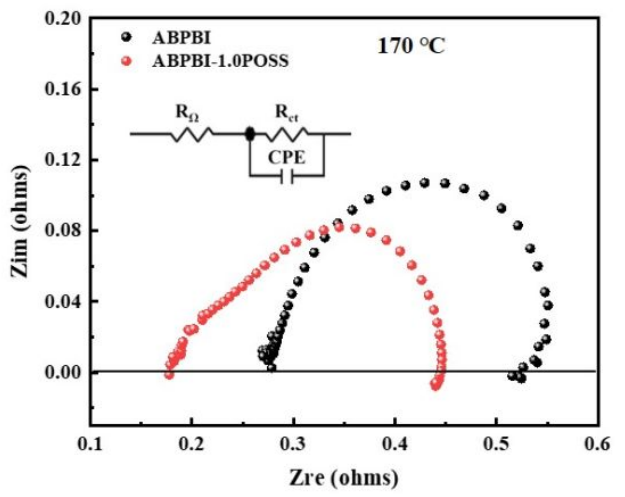

(B)

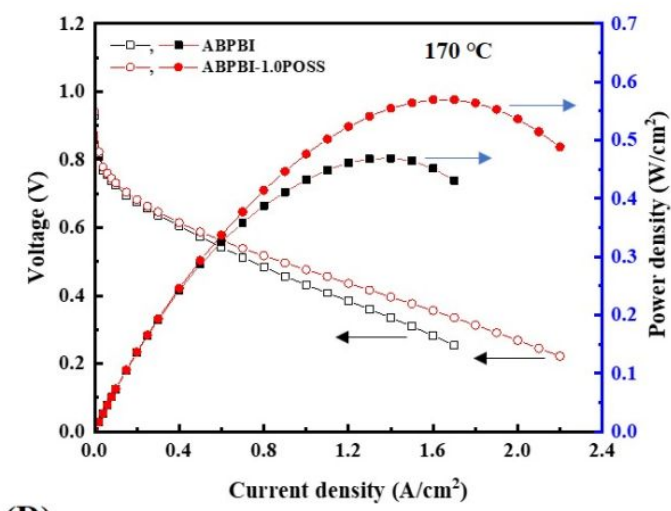

(D)

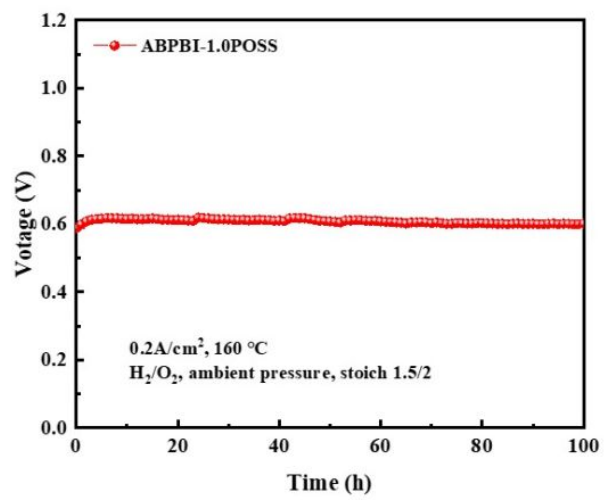

Fig. 5 (A) Proton conductivities and activation energy $\left(E_{\mathrm{a}}\right)$ values of the PA-doped ABPBI and ABPBI-POSS membranes in the temperature range of $120-180{ }^{\circ} \mathrm{C}$ under anhydrous atmosphere; (B) Polarization and power density curves from the single cell tests conducted under non-humidified $\mathrm{H}_{2} / \mathrm{O}_{2}$ at $170{ }^{\circ} \mathrm{C}$; (C) EIS measurements of ABPBI and ABPBI-1.0POSS membranes based single cells at $0.6 \mathrm{~V}$ after activation;

(D) Stability test of the ABPBI-1.0POSS based single cell at a constant current load of $0.2 \mathrm{~A} / \mathrm{cm}^{2}$.

The single cell performance characteristics of the ABPBI (thickness of $120 \mu \mathrm{m}$ ) and ABPBI-1.0POSS (thickness of $110 \mu \mathrm{m}$ ) membranes were investigated at $130{ }^{\circ} \mathrm{C}$ 
(Fig. S6) and $170^{\circ} \mathrm{C}$ (Fig. 5B), respectively. As shown in both figures, the open circuit voltages of both ABPBI and ABPBI-1.0POSS membranes were above $0.9 \mathrm{~V}$, indicating that the membranes effectively prevent the undesirable gas permeation. The ABPBI1.0POSS membrane achieved peak power values of approximately $300 \mathrm{~mW} / \mathrm{cm}^{2}$ at 130 ${ }^{\circ} \mathrm{C}$ and $570 \mathrm{~mW} / \mathrm{cm}^{2}$ at $170{ }^{\circ} \mathrm{C}$, nearly 1.3 and 1.2 times greater than those obtained with the ABPBI membrane. These power density values are comparable to those of the Sn-PA embedded ABPBI membranes [43] and are even higher than those of the clayembedding ABPBI and PBI membranes [16, 44]. The resistances of the two MEAs were determined in the single cell setup at $0.6 \mathrm{~V}$ by in situ impedance measurements, as shown in Fig. 5C. Previous work has shown that $R_{\mathrm{ct}}$ (charge transfer resistance) is strongly related to the methods used for the MEA fabrication [45]. Thus, the $R_{\mathrm{ct}}$ values of the ABPBI-1.0POSS $\left(0.28 \Omega \cdot \mathrm{cm}^{2}\right)$ and the ABPBI $\left(0.27 \Omega \bullet \mathrm{cm}^{2}\right)$ membranes are almost identical because the same method was used for the preparation of both of these MEAs. Meanwhile, the $R_{\Omega}$ (cell resistances) value of the ABPBI-1.0POSS $\left(0.17 \Omega \bullet \mathrm{cm}^{2}\right)$ is obviously lower than the ABPBI membrane $\left(0.28 \Omega \cdot \mathrm{cm}^{2}\right)$, implying that ABPBI1.0POSS membrane has a higher proton conductivity, which is consistent with the results presented in Fig. 5A.

The stability of the single cell based on the ABPBI-1.0POSS membrane was tested under constant current conditions at $160^{\circ} \mathrm{C}$ for 100 h. As is shown in Fig. 5D, in the first $5 \mathrm{~h}$, the single cell voltage continued to rise because the PA on the membrane diffuses to the catalytic layer and increases the electrochemically active area [34]. Then, the voltage dropped slightly due to the loss of some free PA in the membrane and the 
decrease in the mass transfer [46]. The stabilized voltage with less than $2.0 \%$ voltage loss after $60 \mathrm{~h}$ indicates that the ABPBI-1.0POSS membrane has excellent durability and can be used in HT-PEMFCs. Generally, the star copolymer membrane-based MEA exhibits superior single cell performance under high temperatures and anhydrous conditions, suggesting that this approach is an efficient method for optimizing PA-PBI membranes for use as high-temperature PEMs.

\section{Conclusions}

The ABPBI-POSS star copolymers were successfully prepared via an in-situ synthesis procedure for high-temperature PEMs. The beneficial effects of the star copolymer resulted in the reduced intrinsic viscosity and enlarged free volume as well as the reinforcement of POSS nanoparticles in the obtained composites, and the composite membranes showed improved film-forming property, water absorbilities, acid retentivities, and mechanical properties. For the composite membrane with the optimal G-POSS content $(1.0 \mathrm{wt} \%)$ with the removal of free PA to the extent possible, the ABPBI-1.0POSS based single cell achieved the power density of $570 \mathrm{~mW} / \mathrm{cm}^{2}$ under non-humidified $\mathrm{H}_{2} / \mathrm{O}_{2}$ at $170{ }^{\circ} \mathrm{C}$, which was not only 1.3 times higher than that of the pristine ABPBI sample in this work but also comparable to the values obtained for the other ABPBI composite membranes reported in the literature. Thus, this study provides a simple method for the preparation of PA-PBI-based HT-PEMs with a good balance between mechanical and film-forming properties.

\section{Acknowledgments}


This work was financially supported by the National Natural Science Foundation of China (NSFC) (Nos. 21905083 and 51902096) and the Hubei Provincial R\&D Foundation (Nos. 2018CFB412, 2019CFB304 and 201906A07).

\section{References}

[1] Y M Lee. Fuel cells: operating flexibly. Nature Energy. 2016; 1: 16136. https://doi.org/10.1038/nenergy.2016.136

[2] Q Li, J O Jensen, R F Savinell, et al. High temperature proton exchange membranes based on polybenzimidazoles for fuel cells. Progress in Polymer Science. 2009; 34: 449-477. https://doi.org/10.1016/j.progpolymsci.2008.12.003

[3] R Rosli, A B Sulong, W R W Daud, et al. A review of high-temperature proton exchange membrane fuel cell (HT-PEMFC) system. International Journal of Hydrogen Energy. 2017; 42: 9293-9314. https://doi.org/10.1016/j.ijhydene.2016.06.211

[4] N Shaari, S K Kamarudin. Recent advances in additive-enhanced polymer electrolyte membrane properties in fuel cell applications: An overview. International Journal of Energy Research. 2019; 43: 2756-2794. https://doi.org/10.1002/er.4348

[5] C Wang, S Wang, L Peng, et al. Recent Progress on the Key Materials and Components for Proton Exchange Membrane Fuel Cells in Vehicle Applications. Energies. 2016; 9: 603. https://doi.org/10.3390/en9080603

[6] A R Kim, J C Gabunada, D J Yoo. Amelioration in physicochemical properties and single cell performance of sulfonated poly(ether ether ketone) block copolymer composite membrane using sulfonated carbon nanotubes for intermediate humidity fuel 
cells. International Journal of Energy Research. 2019; 43: 2974-2989. https://doi.org/10.1002/er.4494

[7] H Liang, H Su, B G Pollet, et al. Development of membrane electrode assembly for high temperature proton exchange membrane fuel cell by catalyst coating membrane method. Journal of Power Sources. 2015; 288: 121-127. https://doi.org/10.1016/j.jpowsour.2015.04.123

[8] S Wang, S Peng, Z Li, et al. Comprehensive performance enhancement of polybenzimidazole based high temperature proton exchange membranes by doping with a novel intercalated proton conductor. International Journal of Hydrogen Energy. 2018; 43: 9994-10003. https://doi.org/10.1016/j.ijhydene.2018.04.089

[9] P Sun, Z Li, S Wang, et al. Performance enhancement of polybenzimidazole based high temperature proton exchange membranes with multifunctional crosslinker and highly sulfonated polyaniline. Journal of Membrane Science. 2018; 549: 660-669. https://doi.org/10.1016/j.memsci.2017.10.053

[10] M Mamlouk, K Scott. Phosphoric acid-doped electrodes for a PBI polymer membrane fuel cell. International Journal of Energy Research. 2011; 35: 507-519. https://doi.org/10.1002/er.1708

[11] R Rath, P Kumar, L Unnikrishnan, et al. Current Scenario of Poly (2, 5Benzimidazole)(ABPBI) as Prospective PEM for Application in HT-PEMFC. Polymer Reviews. 2019; 1-51. https://doi.org/10.1080/15583724.2019.1663211

[12] D C Villa, S Angioni, S D Barco, et al. Polysulfonated Fluoro-oxyPBI Membranes for PEMFCs: An Efficient Strategy to Achieve Good Fuel Cell Performances with Low 
H3PO4 Doping Levels. Adv Energy Mater. 2014; 4: 1220-1225. https://doi.org/10.1002/aenm.201301949

[13] S Angioni, D C Villa, S D Barco, et al. Polysulfonation of PBI-based membranes for HT-PEMFCs: A possible way to maintain high proton transport at a low H3PO4 doping level. Journal of Materials Chemistry A. 2013; 2: 663-671. https://doi.org/10.1039/C3TA12200J

[14] D W Shin, M D Guiver, Y M Lee. Hydrocarbon-based polymer electrolyte membranes: importance of morphology on ion transport and membrane stability. $\begin{array}{llll}\text { Chemical } & \text { reviews. } & \text { 2017; } & \text { 4759-4805. }\end{array}$ https://doi.org/10.1021/acs.chemrev.6b00586

[15] X Sun, S C Simonsen, T Norby, et al. Composite Membranes for High Temperature PEM Fuel Cells and Electrolysers: A Critical Review. Membranes. 2019; 9: 83. https://doi.org/10.3390/membranes9070083

[16] K Hooshyari, M Moradi, P Salarizadeh. Novel nanocomposite membranes based on PBI and doped-perovskite nanoparticles as a strategy for improving PEMFC performance at high temperatures. International Journal of Energy Research. 2020; 44: 2617-2633. https://doi.org/10.1002/er.5001

[17] M Hu, T Li, S Neelakandan, et al. Cross-linked polybenzimidazoles containing hyperbranched cross-linkers and quaternary ammoniums as high-temperature proton exchange membranes: Enhanced stability and conductivity. Journal of Membrane Science. 2020; 593: 117435. https://doi.org/10.1016/i.memsci.2019.117435 
[18] Q Li, D Aili, H A Hjuler, et al. High temperature polymer electrolyte membrane fuel cells. Springer, Cham. 2016.

[19] V Vijayakumar, K Kim, S Y Nam. Recent Advances in Polybenzimidazole (PBI)based Polymer Electrolyte Membranes for High Temperature Fuel Cell Applications. Applied Chemistry for Engineering. 2019; 30: 643-651. https://doi.org/10.14478/ace.2019.1080

[20] N Hadjichristidis, M Pitsikalis, H Iatrou, et al. Polymers with Star-Related Structures: Synthesis, Properties, and Applications. Polymer science: a comprehensive reference. 2012; 6: 29-111. https://doi.org/10.1016/B978-0-444-53349-4.00161-8 [21] L J Fetters, A D Kiss, D S Pearson, et al. Rheological behavior of star-shaped polymers. Macromolecules. 1993; 26: 647-654. https://doi.org/10.1021/ma00056a015 [22] H Xie, D Tao, X Xiang, et al. Synthesis and properties of highly branched starshaped sulfonated block poly(arylene ether)s as proton exchange membranes. Journal of Membrane $\quad$ Science. 2015; 473: 226-236. https://doi.org/10.1016/i.memsci.2014.09.015

[23] D Liu, D Tao, J Ni, et al. Synthesis and properties of highly branched sulfonated poly (arylene ether) s with flexible alkylsulfonated side chains as proton exchange membranes. Journal of Materials Chemistry C. 2016; 4: 1326-1335. https://doi.org/10.1039/C5TC04033G

[24] S Neelakandan, D Liu, L Wang, et al. Highly branched poly(arylene ether)/surface functionalized fullerene-based composite membrane electrolyte for DMFC applications. 
International Journal of Energy Research. 2019; 43: 6056-6056. https://doi.org/10.1002/er.4536

[25] M Hu, J Ni, B Zhang, et al. Crosslinked polybenzimidazoles containing branching structure as membrane materials with excellent cell performance and durability for fuel cell applications. Journal of Power Sources. 2018; 389: 222-229. https://doi.org/10.1016/j.jpowsour.2018.04.025

[26] Q Liu, S Quan, N Na, et al. Novel octopus shaped organic-inorganic composite membranes for PEMFCs. International Journal of Hydrogen Energy. 2016; 41: 1616016166. https://doi.org/10.1016/j.ijhydene.2016.05.078

[27] D B Cordes, P D Lickiss, F Rataboul. Recent developments in the chemistry of cubic polyhedral oligosilsesquioxanes. Chemical Reviews. 2010; 110: 2081-2173. https://doi.org/10.1021/cr900201r

[28] F Zhang, Z Tu, J Yu, et al. Impregnation of imidazole functionalized polyhedral oligomeric silsesquioxane in polymer electrolyte membrane for elevated temperature fuel cells. Rsc Advances. 2013; 3: 5438-5446. https://doi.org/10.1039/c3ra40640g [29] H Pan, Y Zhang, H Pu, et al. Organic-inorganic hybrid proton exchange membrane based on polyhedral oligomeric silsesquioxanes and sulfonated polyimides containing benzimidazole. Journal of Power Sources. 2014; 263: 195-202. https://doi.org/10.1016/j.jpowsour.2014.04.055

[30] D Aili, T Allward, S M Alfaro, et al. Polybenzimidazole and sulfonated polyhedral oligosilsesquioxane composite membranes for high temperature polymer electrolyte 
membrane fuel cells. Electrochimica Acta. 2014; 140: 182-190. https://doi.org/10.1016/j.electacta.2014.03.047

[31] P Zhang, W Li, L Wang, et al. Polydopamine-modified sulfonated polyhedral oligomeric silsesquioxane: An appealing nanofiller to address the trade-off between conductivity and stabilities for proton exchange membrane. Journal of Membrane Science. 2020; 596: 117734. https://doi.org/10.1016/j.memsci.2019.117734

[32] C Liu, Z Wu, Y Xu, et al. Facile one-step fabrication of sulfonated polyhedral oligomeric silsesquioxane cross-linked poly(ether ether ketone) for proton exchange membranes. Polymer Chemistry. 2018; 9: 3624-3632. https://doi.org/10.1039/c8py00650d

[33] J Zhang, F Chen, X Ma, et al. Sulfonated polymers containing polyhedral oligomeric silsesquioxane (POSS) core for high performance proton exchange membranes. International Journal of Hydrogen Energy. 2015; 40: 7135-7143. https://doi.org/10.1016/j.ijhydene.2015.02.090

[34] S Martin, Q Li, T Steenberg, et al. Binderless electrodes for high-temperature polymer electrolyte membrane fuel cells. Journal of Power Sources. 2014; 272: 559566. https://doi.org/10.1016/j.jpowsour.2014.08.112

[35] A Nag, M A Ali, M Watanabe, et al. Dataset of various characterizations for novel bio-based plastic poly(benzoxazole-co-benzimidazole) with ultra-low dielectric constant. Data in Brief. 2019; 25: 104114. https://doi.org/10.1016/j.dib.2019.104114 
[36] S B Acar, M Ozcelik, T Uyar, et al. Polyhedral oligomeric silsesquioxane-based hybrid networks obtained via thiol-epoxy click chemistry. Iranian Polymer Journal. 2017; 26: 405-411. https://doi.org/10.1007/s13726-017-0529-x

[37] Z Wang, Y Chen, S Chen, et al. Preparation and characterization of a soy protein based bio-adhesive crosslinked by waterborne epoxy resin and polyacrylamide. RSC Advances. 2019; 9: 35273-35279. https://doi.org/10.1039/C9RA05931H

[38] Y Tang, B Wang, X Lu, et al. Study on the Synthesis and Solubi lity of Polybenzimidazole and Derivatives. Materials Reports. 2009; 23: 21-24. https://doi.org/10.3321/j.issn:1005-023X.2009.06.007

[39] J Fang, X Lin, D Cai, et al. Preparation and characterization of novel pyridinecontaining polybenzimidazole membrane for high temperature proton exchange membrane fuel cells. Journal of Membrane Science. 2016; 502: 29-36. https://doi.org/10.1016/j.memsci.2015.12.006

[40] J A Asensio, P Gómez-Romero. Recent Developments on Proton Conduc-ting Poly (2, 5-benzimidazole)(ABPBI) Membranes for High Temperature Poly-mer Electrolyte Membrane Fuel Cells. Fuel Cells. 2005; 5: 336-343. https://doi.org/10.1002/fuce.200400081

[41] S Li, J R Fried, J Colebrook, et al. Molecular simulations of neat, hydrated, and phosphoric acid-doped polybenzimidazoles. Part 1: Poly $\left(2,2^{\prime}\right.$-m-phenylene-5,5'bibenzimidazole) (PBI), poly(2,5-benzimidazole) (ABPBI), and poly(p-phenylene benzobisimidazole) (PBDI). Polymer. 2010; 51: 5640-5648. https://doi.org/10.1016/j.polymer.2010.09.021 
[42] A S Rewar, H D Chaudhari, R Illathvalappil, et al. New Approach of Blending Polymeric Ionic Liquid with Polybezimidazole (PBI) for Enhancing Physical and Electrochemical Properties. Journal of Materials Chemistry A. 2014; 2: 14449-14458. https://doi.org/10.1039/C4TA02184C

[43] Y-C Chiang, D-S Tsai, Y-H Liu, et al. PEM fuel cells of poly (2, 5-benzimidazole) ABPBI membrane electrolytes doped with phosphoric acid and metal phosphates. Materials Chemistry and Physics. 2018; 216: 485-490. https://doi.org/10.1016/j.matchemphys.2018.06.035

[44] X Zhang, X Fu, S Yang, et al. Design of sepiolite-supported ionogel-embedded composite membranes without proton carrier wastage for wide-temperature-range operation of proton exchange membrane fuel cells. Journal of Materials Chemistry A. 2019; 7: 15288-15301. https://doi.org/10.1039/C9TA03666K

[45] $\mathrm{H} \mathrm{Su}, \mathrm{Q} \mathrm{Xu}, \mathrm{J}$ Chong, et al. Eliminating micro-porous layer from gas diffusion electrode for use in high temperature polymer electrolyte membrane fuel cell. Journal of Power Sources. 2017; 341: 302-308. https://doi.org/10.1016/j.jpowsour.2016.12.029 [46] Y Devrim, A Albostan, H Devrim. Experimental investigation of CO tolerance in high temperature PEM fuel cells. International Journal of Hydrogen Energy. 2018; 43: 18672-18681. https://doi.org/10.1016/i.ijhydene.2018.05.085 


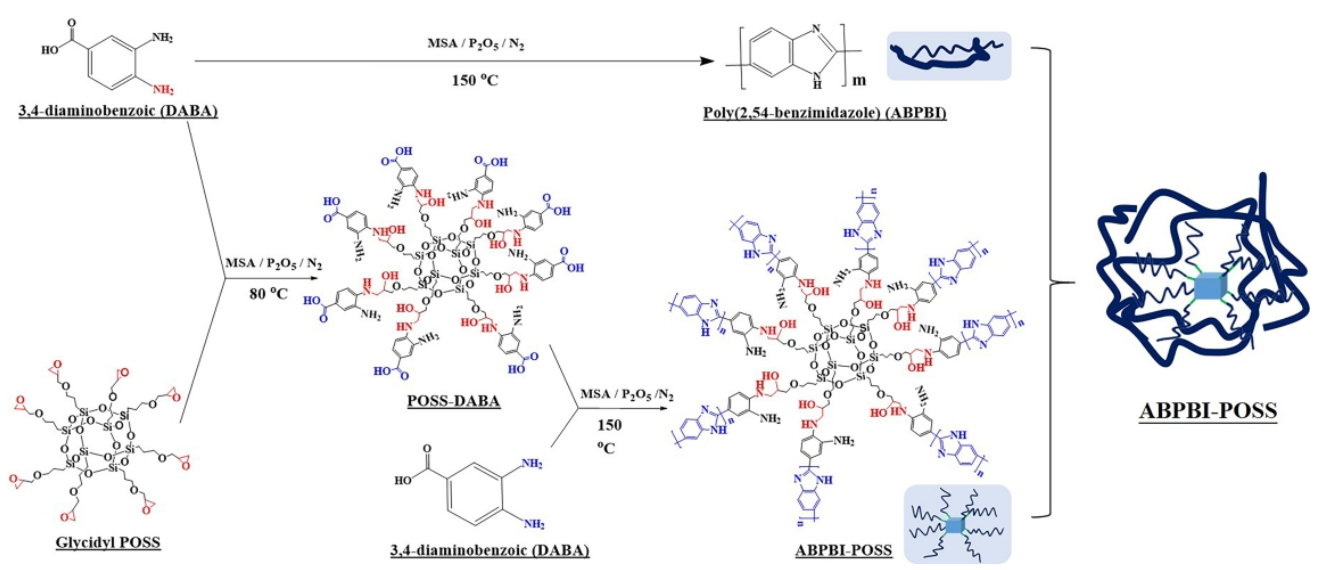

Scheme 1 

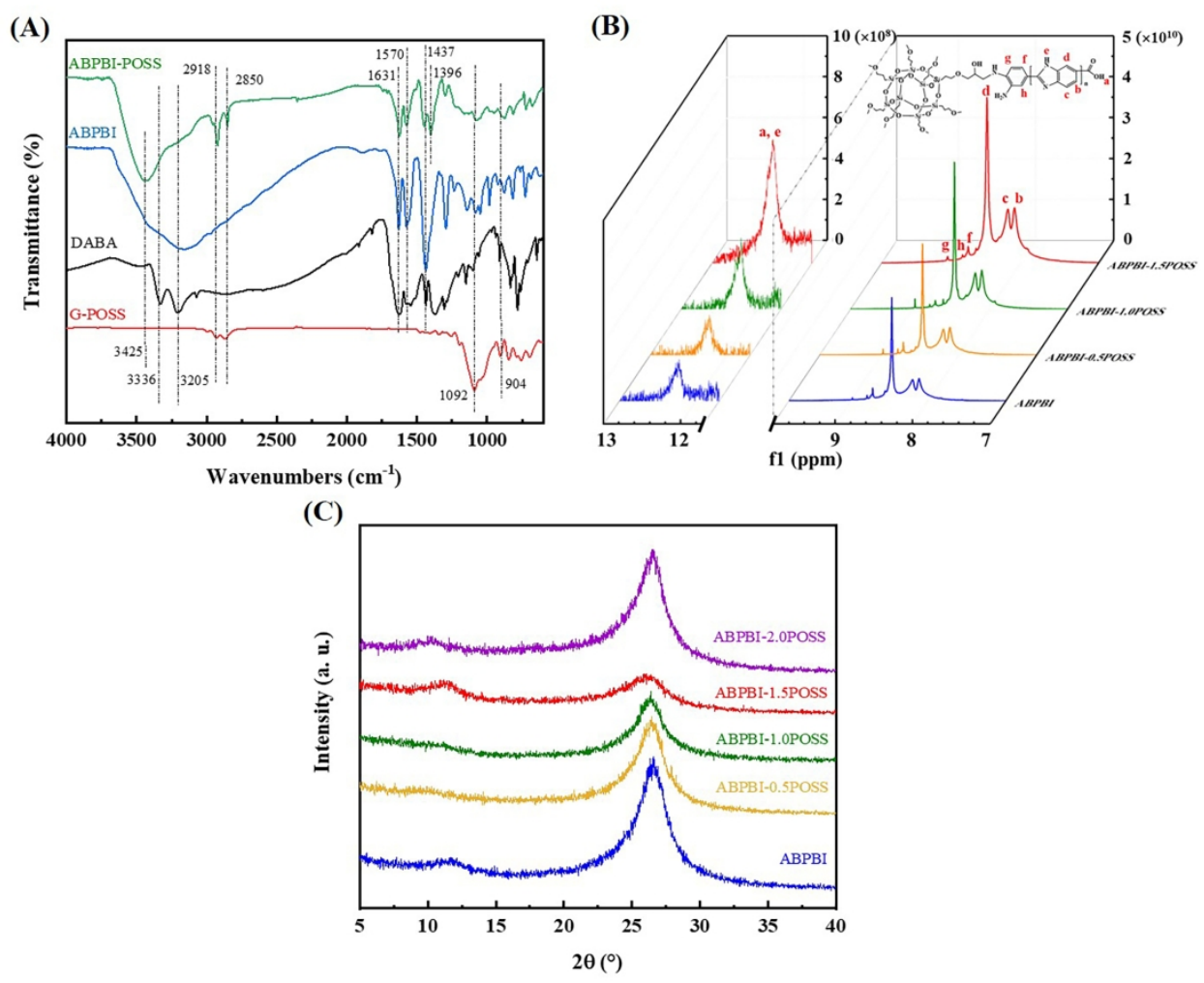

Fig. 1

John Wiley \& Sons 

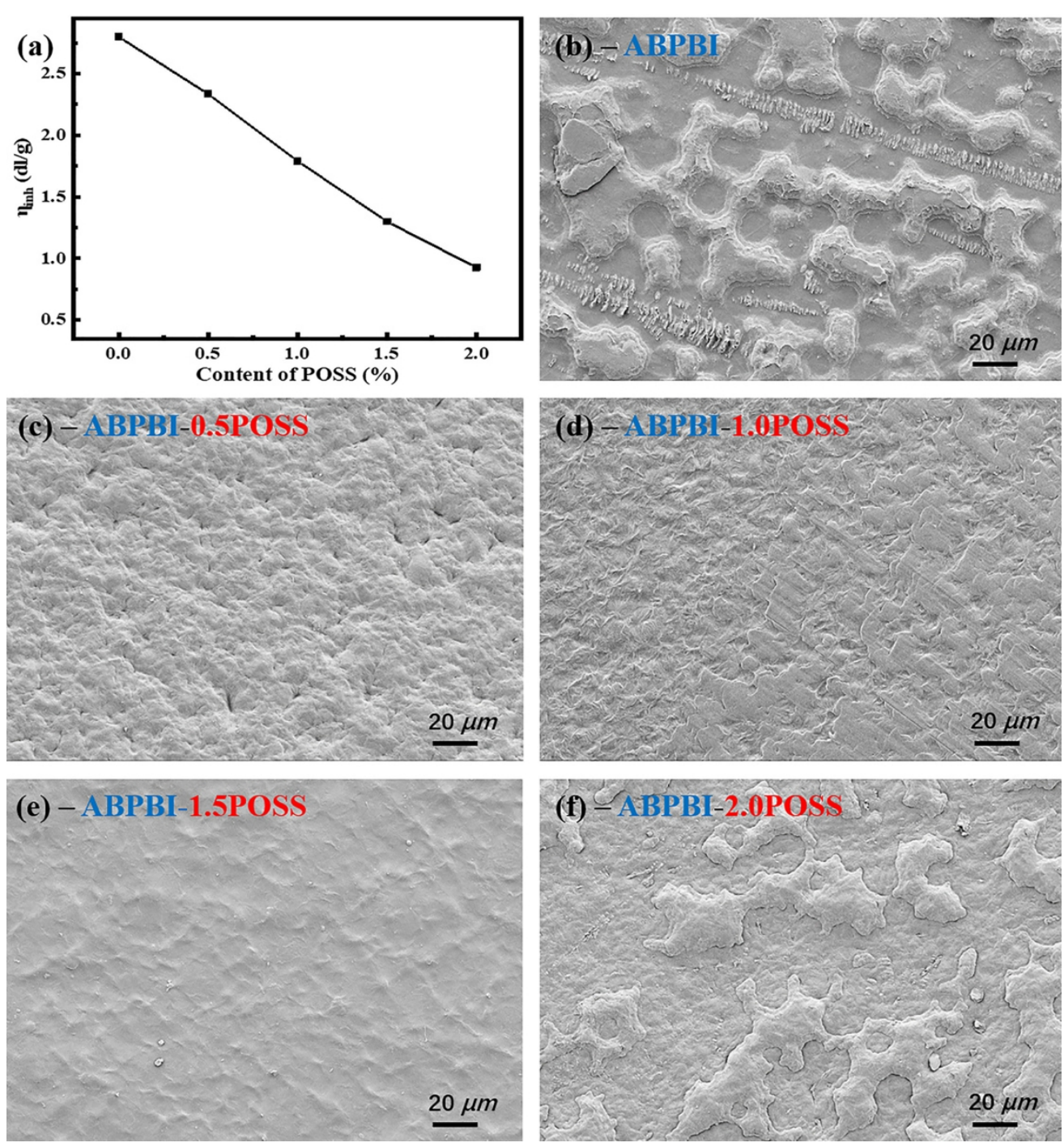

Fig. 2 

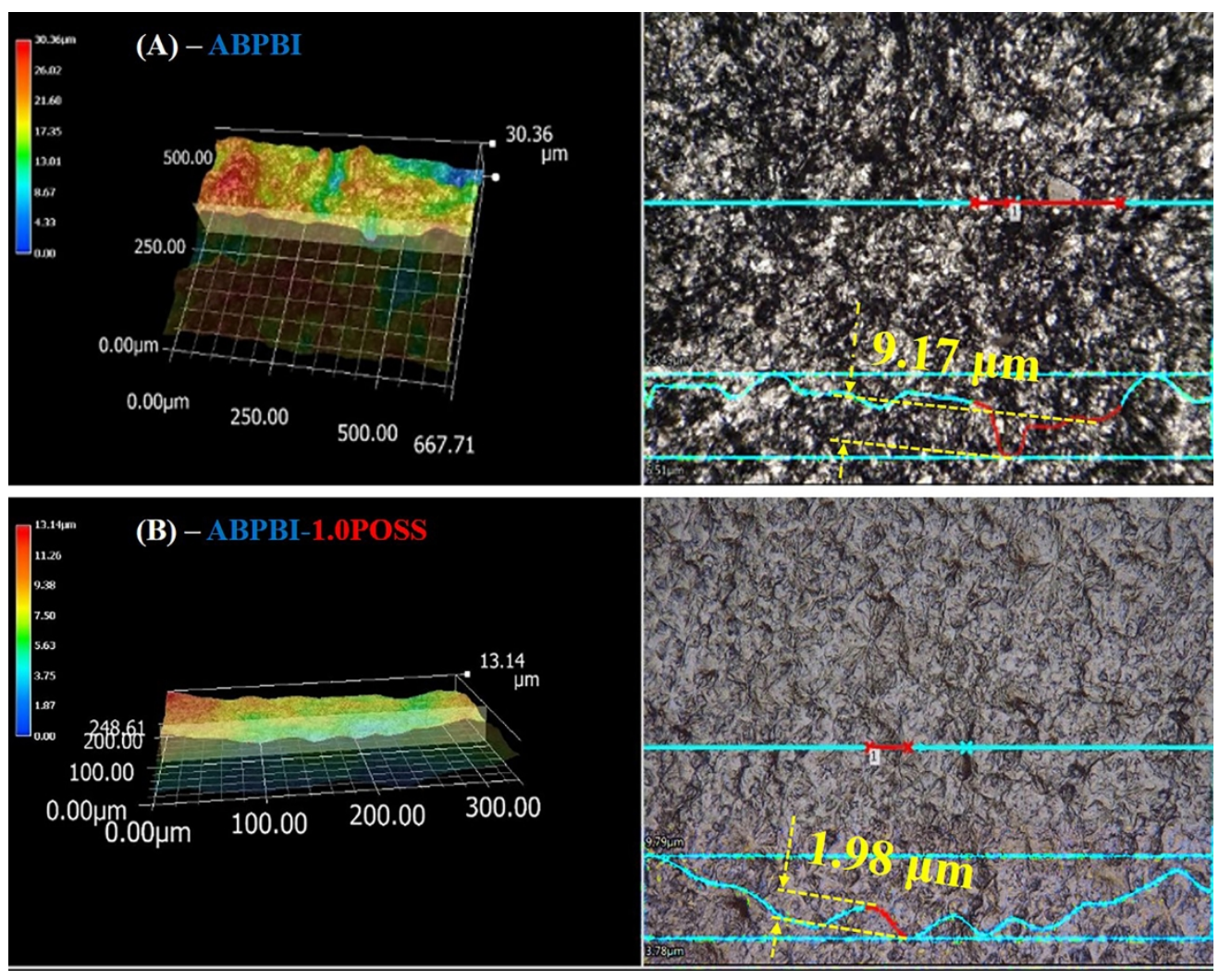

Fig. 3 
(a)

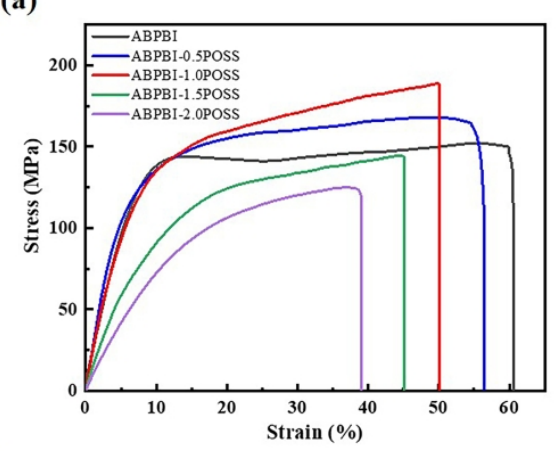

(c)

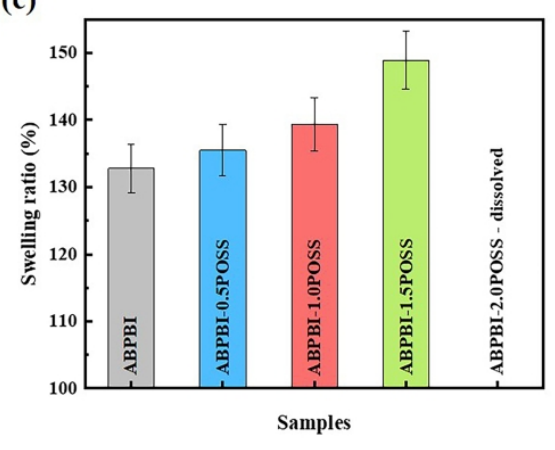

(b)

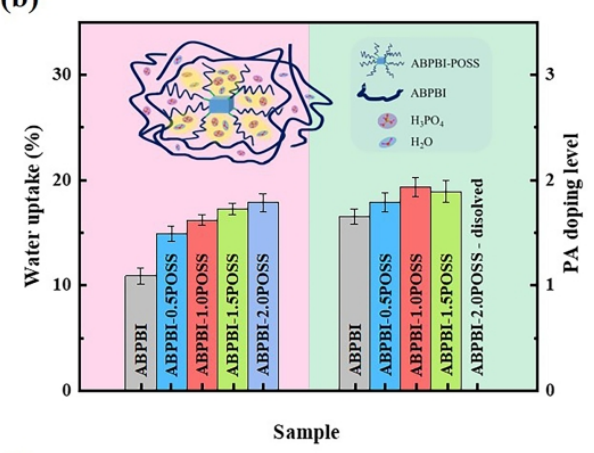

(d)

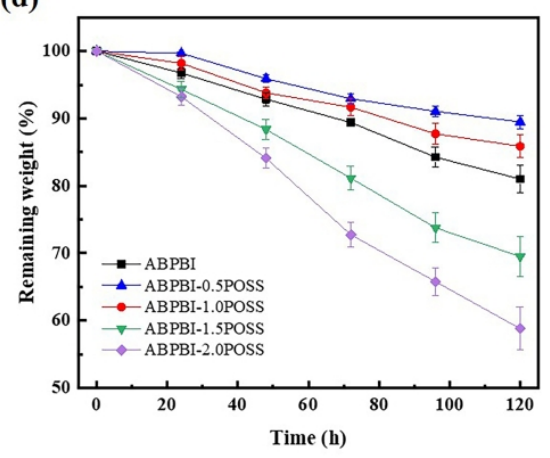

Fig. 4 
(A)

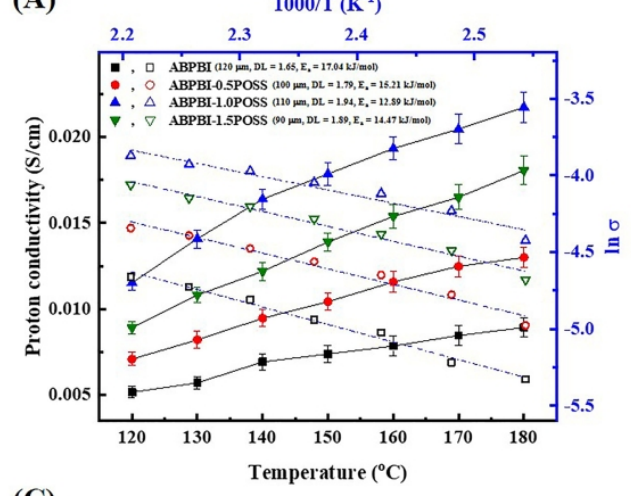

(C)

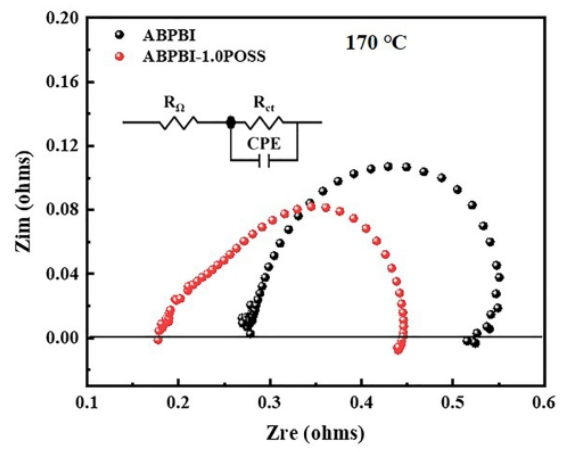

(B)

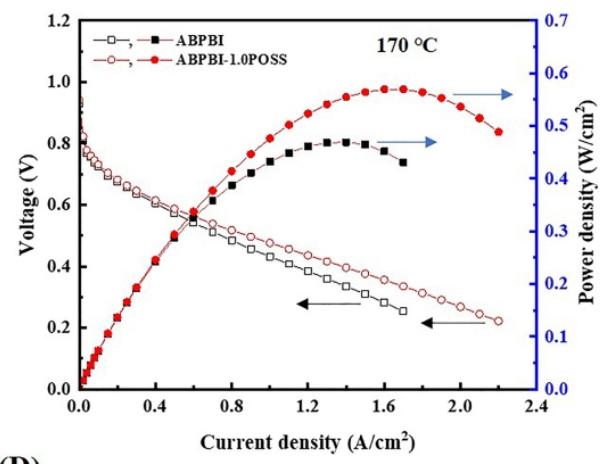

(D)

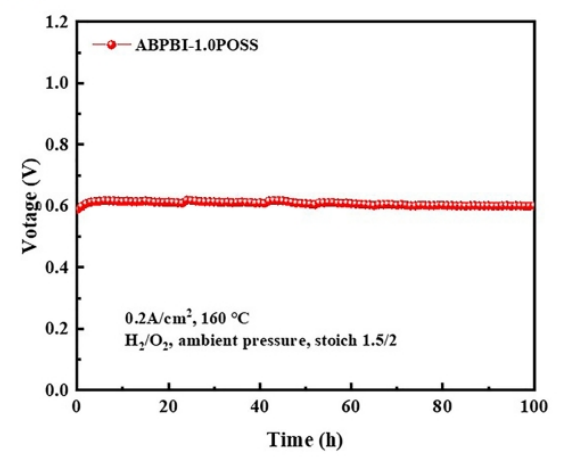

Fig. 5 